\title{
Estimation of surface soil moisture and roughness from multi-angular ASAR imagery in the Watershed Allied Telemetry Experimental Research (WATER)
}

\author{
S. G. Wang ${ }^{1,2}$, X. Li ${ }^{1}$, X. J. Han ${ }^{1}$, and R. Jin ${ }^{1}$ \\ ${ }^{1}$ Cold and Arid Regions Environmental and Engineering Research Institute, Chinese Academy of Sciences, \\ Lanzhou, 730000, China \\ ${ }^{2}$ Graduate University of Chinese Academy of Sciences, Beijing, 100039, China
}

Received: 11 May 2010 - Published in Hydrol. Earth Syst. Sci. Discuss.: 8 June 2010

Revised: 25 March 2011 - Accepted: 25 April 2011 - Published: 6 May 2011

\begin{abstract}
Radar remote sensing has demonstrated its applicability to the retrieval of basin-scale soil moisture. The mechanism of radar backscattering from soils is complicated and strongly influenced by surface roughness. Additionally, retrieval of soil moisture using AIEM (advanced integrated equation model)-like models is a classic example of underdetermined problem due to a lack of credible known soil roughness distributions at a regional scale. Characterization of this roughness is therefore crucial for an accurate derivation of soil moisture based on backscattering models. This study aims to simultaneously obtain surface roughness parameters (standard deviation of surface height $\sigma$ and correlation length $\mathrm{cl}$ ) along with soil moisture from multi-angular ASAR images by using a two-step retrieval scheme based on the AIEM. The method firstly used a semi-empirical relationship that relates the roughness slope, $Z s\left(Z s=\sigma^{2} / \mathrm{cl}\right)$ and the difference in backscattering coefficient $(\Delta \sigma)$ from two ASAR images acquired with different incidence angles. Meanwhile, by using an experimental statistical relationship between $\sigma$ and $\mathrm{cl}$, both these parameters can be estimated. Then, the deduced roughness parameters were used for the retrieval of soil moisture in association with the AIEM. An evaluation of the proposed method was performed in an experimental area in the middle stream of the Heihe River Basin, where the Watershed Allied Telemetry Experimental Research (WATER) was taken place. It is demonstrated that the proposed method is feasible to achieve reliable estimation of soil water content. The key challenge is the presence of vegetation cover, which significantly impacts the estimates of surface roughness and soil moisture.
\end{abstract}

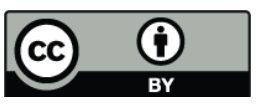

Correspondence to: $\mathrm{X} . \mathrm{Li}$

(lixin@1zb.ac.cn)

\section{Introduction}

Surface soil moisture $(\mathrm{mv})$ is important in agronomic, hydrological, and meteorological processes at all spatial scales. It plays a key role in water stress detection and irrigation management, especially for arid and semi-arid regions. The ability of inferring $m v$ using both active and passive microwave techniques has been intensively demonstrated (Baghdadi et al., 2008; Jackson et al., 1995, 2002; Kerr et al., 2001; Moran et al., 2004; Njoku and Entekhabi, 1996; Njoku et al., 2003; Parajka et al., 2009; Sinclair and Pegram, 2010; Su et al., 1997; Ulaby et al., 1982, 1986; Wigneron et al., 2003, 2007). It is well known that space-borne microwave radiometers and scatterometers possess the advantage of high revisit capacity but deficient in coarse spatial resolution (Brocca et al., 2010; Wagner et al., 1999, 2007). On the contrary, synthetic aperture radar (SAR) sensors have the capability to provide finer spatial resolution, on the order of tens of meters, meeting most spatial requirements for watershed management and hydrological applications.

Radar systems emit pulses and receive echoes backscattered from the illuminated areas. The intensity value of each pixel is proportional to the radar backscattering coefficient $\left(\sigma^{0}\right)$, which depends on several factors, including the instrument's technical specifications (frequency and polarization), terrain, dielectric characteristics $\left(\varepsilon_{\mathrm{r}}\right.$; strongly related to the soil water content) and the geometrical structure (roughness) of the target surface.

Three categories of methods were developed to investigate the relationship between land surface properties and SAR observed backscattering coefficient. The first kind is theoretical scattering model, which was derived and employed to gain insight into the interaction of microwave propagation with natural surfaces based on physical laws, including the Kirchhoff approximation (KA), which consists of the geometrical

Published by Copernicus Publications on behalf of the European Geosciences Union. 
optics model (GOM) and physical optics model (POM), the small perturbation model (SPM) (Ulaby et al., 1982), and the integral equation model (IEM) (Fung et al., 1992; Fung, 1994). The IEM unites the KA and the SPM and was verified by laboratory measurements of bistatic scattering from surfaces with small, intermediate and large scale roughness. The advanced IEM (AIEM) improves the calculation accuracy of scattering coefficient by keeping the absolute phase term in Greens function which was neglected by IEM (Chen et al., 2003; Wu et al., 2001). In principle, the dielectric constant of the soil surface and hence the soil water content can be estimated from the mathematical inversion of these models with the requirement of some restrictive assumptions. The IEM and the AIEM were often used for bare or sparse vegetation soils.

In contrast, the second kind method is empirical approach, with little physics behind it. Traditionally, some known in situ soil moisture measurements and corresponding radar backscattering coefficients were used to calibrate a simple form to predict unknown soil moisture (Ulaby et al., 1986). This type of connection was evolved with increasingly fruitful datasets in recent years (Baghdadi et al., 2006a; Holah et al., 2005). In addition, some sophisticated empirical methods have been proposed as well, with varying degrees of success (Baghdadi and Zribi, 2006). For example, Oh et al. (1992, 2002) separated the individual effects of roughness, vegetation, topography, and soil moisture on radar response using multi-frequency and multi-polarization measurements. Dubois et al. (1995) delineated the contributions of all combinations of surface conditions (roughness and vegetation) and radar configurations (frequency, polarization, and incidence angle) to the co-polarized backscattering coefficients $\sigma_{\mathrm{HH}}^{0}$ and $\sigma_{\mathrm{VV}}^{0}$. However, these empirical relationships are site-specific and may not be applicable to datasets other than those used for development (Dubois et al., 1995).

To circumvent this problem, semi-empirical backscattering models may be more useful in determination of land surface geophysical parameters including soil moisture which represent a compromise between the complexity of the theoretical models and the simplicity of empirical models. They are an improvement on empirical models as they start from a physical background and then use simulated or experimental data sets to simplify the theoretical backscattering models (D'Urso and Minacapilli, 2006; Loew et al., 2006; Shi et al., 1997; Zribi et al., 2006).

In the IEM and AIEM, surface roughness is an essential input, thus, if only a single configuration (e.g., one polarization, one frequency) of radar data is available, roughness parameters should be known as a priori information in order to retrieve soil moisture using these models. Unfortunately, field measuring surface roughness is very time-consuming and almost impractical at the regional scale. Moreover, appreciable inaccuracies may occur due to various deployments of instrumentation, sampling strategy, and the ambiguous scale effect during field campaigns and data post-processing
(Bryant et al., 2007; Davidson et al., 2000). Hence, it is critical to obtain appropriate physical model-dependent surface roughness information at remote-sensing spatial scales in the context of soil moisture inversion.

Generally speaking, surface roughness is statistically characterized by three parameters: the standard deviation of surface height $(\sigma)$, the correlation length $(\mathrm{cl})$, and the autocorrelation function type (ACF). From pixel to pixel, these parameters vary remarkably, moreover, the significant influence of surface roughness on scattering properties still limits the ability to correctly infer $m v$ values unless detailed roughness measurements or estimates are available (Lievens et al., 2009; Verhoest et al., 2008; Zribi et al., 2005). Su et al. (1997) demonstrated that calibration of surface roughness could reduce the number of unknowns in the IEM, resulting in successful soil moisture retrievals. Baghdadi et al. $(2002,2004,2006$ b) empirically calibrated the cl values based on the IEM, a large number of SAR images, and corresponding field measurements. Therefore, empirical relationships were obtained between $\sigma$ and cl depending on frequency, polarization, and incidence angle, thus reducing the problem to the estimation of only one parameter (Baghdadi et al., 2006b). Álvarez-Mozos et al. (2008) applied the approach developed by Baghdadi et al. (2006b) to Radarsat-1 data and obtained promising soil moisture retrieval results. Through calibration of roughness parameters, two-step retrieval schemes (Lievens et al., 2011; Saleh et al., 2009) were proposed to obtain reliable soil moisture estimates. Furthermore, Zribi and Dechambre (2002) revealed the merits of using multi-angular SAR observations for surface roughness estimation and proposed a $Z s$-index that integrates $\sigma$ and cl. It was demonstrated that the difference in backscattering coefficients between two incidence angles is very sensitive to the Zs-index. Rahman et al. $(2007,2008)$ also indicated both roughness parameters and $m v$ can be inferred via multi-angular radar images instead of using ancillary data. Besides, dependent on time series SAR imagery, change detection method is a simple and effective way to capture soil moisture variations. In this method, a dry reference image is subtracted from each individual SAR image in an attempt to correct for roughness and vegetation effects (Mladenova et al., 2010; Pathe et al., 2009; Wagner et al., 1999, 2007).

The objective of this paper is to develop and evaluate an effective method that could acquire surface roughness based solely on multi-angle SAR data, and the estimated roughness can be further used in the backscatter models to retrieve soil water content. The strategy is a two-step retrieval scheme. Firstly, a semi-empirical relationship was deduced from AIEM simulations. Combined with a calibrated scheme within $\sigma$ and cl proposed by Baghdadi et al. (2006b), roughness parameters for each grid cell can be estimated from multi-angular ASAR images. Once $\sigma$ and $\mathrm{cl}$ were obtained, soil moisture can then be retrieved by using the AIEM. This paper is organized into four sections. In Sect. 2, which follows the introduction, the proposed methodology, the study 
site and datasets are described. Section 3 presents the detailed application on estimating both surface roughness and soil moisture over the study area. Then, the retrieved results in terms of soil moisture are validated by in situ measurements and the error sources are analyzed. Finally, Sect. 4 gathers our conclusions.

\section{Method and data}

\subsection{Backscattering model for vegetated rough surface}

For a given incidence angle $\theta$, the backscattering coefficient above canopy $\left(\sigma_{\text {can }}^{0}(\theta), \mathrm{m}^{2} \mathrm{~m}^{-2}\right)$ can be expressed as

$\sigma_{\text {can }}^{0}(\theta)=\sigma_{\text {veg }}^{0}(\theta)+\sigma_{\text {veg }+ \text { soil }}^{0}(\theta)+\gamma^{2}(\theta) \sigma_{\text {soil }}^{0}(\theta)$

where, the first term $\sigma_{\text {veg }}^{0}(\theta)$ represents the backscattering from the vegetation canopy, the second term $\sigma_{\text {veg }+ \text { soil }}^{0}(\theta)$ represents the interaction between the vegetation layer and the soil underneath and accounts for multiple scattering effects, and the third term $\gamma^{2}(\theta) \sigma_{\text {soil }}^{0}(\theta)$ represents the backscattering from the soil layer that is attenuated by the canopy. $\gamma^{2}(\theta)$ is the two-way vegetation transmissivity.

In this study, backscattering from vegetation canopy and the vegetation transmissivity are calculated by the water cloud model (Attema and Ulaby, 1978), since this model is assumed that the vegetation-soil interactions can be neglected, and, therefore,

$\sigma_{\text {can }}^{0}(\theta)=\sigma_{\text {veg }}^{0}(\theta)+\gamma^{2}(\theta) \sigma_{\text {soil }}^{0}(\theta)$

with

$\sigma_{\mathrm{veg}}^{0}=A \mathrm{vwc} \cos (\theta)\left[1-\gamma^{2}(\theta)\right]$

$\gamma^{2}(\theta)=\exp [-2 b v w c / \cos (\theta)]$

where vwc represents the vegetation water content $\left(\mathrm{kg} \mathrm{m}^{-2}\right)$. Parameters $A$ and $b$ depend on the vegetation type, growth condition, and radar frequency.

The backscattering coefficient from the soil layer is calculated by the AIEM which is a physically based radiative transfer model and applicable to a wider range of land surface conditions (Chen et al., 2003; Wu et al., 2001). The AIEM essentially quantifies (or simulates) the backscattering coefficient as a function of the sensor configurations (i.e., radar frequency, polarization, and incidence angle) and land surface parameters (e.g., soil dielectric constant and surface roughness).

In AIEM, the single scattering term is given by

$$
\begin{aligned}
\sigma_{p q}^{\mathrm{S}}= & \frac{k^{2}}{2} \exp \left[-(\sigma)^{2}\left(k_{z}^{2}+k_{\mathrm{sz}}^{2}\right)\right] \sum_{n=1}^{\infty}(\sigma)^{2 n}\left|I_{p q}^{n}\right|^{2} \\
& \frac{W^{(n)}\left(k_{\mathrm{s} x}-k_{x}, k_{\mathrm{s} y}-k_{y}\right)}{n !}
\end{aligned}
$$

$$
\begin{aligned}
I_{p q}^{n} & =\left(k_{\mathrm{s} z}+k_{z}\right)^{n} f_{p q} \exp \left[-(\sigma)^{2} k_{z} k_{\mathrm{s} z}\right] \\
& +\frac{\left(k_{\mathrm{s} z}\right)^{n} F_{p q}\left(-k_{x},-k_{y}\right)+\left(k_{z}\right)^{n} F_{p q}\left(-k_{\mathrm{s} x},-k_{\mathrm{s} y}\right)}{2}
\end{aligned}
$$

with

$k_{x}=k \sin \theta \cos \phi$

$k_{y}=k \sin \theta \sin \phi$

$k_{z}=k \cos \theta$

$k_{\mathrm{s} x}=k \sin \theta_{\mathrm{s}} \cos \phi_{\mathrm{s}}$

$k_{\mathrm{s} y}=k \sin \theta_{\mathrm{s}} \sin \phi_{\mathrm{s}}$

$k_{\mathrm{s} z}=k \cos \theta_{\mathrm{s}}$

where $k$ is the wave number, $I_{p q}^{n}$ is a function of $\theta, \phi, \sigma$ and $\varepsilon_{\mathrm{r}}$ (soil dielectric constant), $F_{p q}$ denotes the complementary field coefficient. $W^{(n)}$ is the Fourier transform of the $n$-th power of the surface correlation function. The subscripts $p$ and $q$ indicate polarization state. $\theta$ and $\phi$ are zenith angle and azimuth angle of the sensor, $\theta_{\mathrm{s}}$ and $\phi_{\mathrm{s}}$ are zenith and azimuth of scattering angle, respectively.

\subsection{Inversion strategy for soil moisture}

In SAR remote sensing applications, sensor configurations are known, while surface roughness and dielectric constant are unknown. Estimation of soil surface parameters was usually implemented by using theoretical models to convert the measured backscatter coefficient into soil surface roughness and moisture. In the current study, the first procedure of soil moisture inversion is to remove the vegetation effect, which can be achieved by using Eqs. (2) to (4). Soil texture and land surface correlation function type can be measured in field and assumed as a priori information. Thereby, the remained three unknown surface parameters are soil moisture $m v$, standard deviation of surface height $\sigma$, and correlation length cl.

Therefore, for inversion of soil moisture, at least three independent backscattering observations are needed. Multifrequency configuration onboard aircraft platform (Bindlish and Barros, 2000), multi-angular, or multi-polarization observing ability of current satellite-borne SAR such as ASAR offer this possibility. However, multi-dimensionality observations are usually highly correlated between each other. Therefore, to increase the robustness for the retrieval process, a two-step inversion strategy is employed in this paper since the multi-angular method is considered.

During the first step, roughness parameters $\sigma$ and $\mathrm{cl}$ are retrieved from multi-angular observations. Zribi and Dechambre (2002) showed that, if all other parameters are kept constant, the difference in backscattering coefficient $(\Delta \sigma$, in $\mathrm{dB})$ between two distinct incidence angles is proportional to the index of the roughness slope, $Z s$, which can be expressed as

$Z s=\sigma^{2} / \mathrm{cl}$ 
Through IEM simulations, it was found that $Z s$ is linked to $\Delta \sigma$ via the following relationship (Zribe and Dechambre, 2002)

$Z s=f\left(\Delta \sigma_{\theta_{1}-\theta_{2}}\right)$

The specific function needs to be obtained through statistical analysis.

Additionally, on the basis of various SAR instrumental configurations and abundant in situ measurements, Baghdadi et al. (2006b) has deduced the calibrated correlation length from SAR images and found a statistical relationship between $\sigma$ and cl, which is

$\mathrm{cl}(\sigma, \theta, \mathrm{pp})=\delta(\sin \theta)^{\mu} \sigma^{(\eta \theta+\xi)}$

The parameters $\delta$ and $\zeta$ depend on the polarization, while $\mu$ and $\eta$ were found to be independent of the polarization. All of them are functions of incident angle $\theta$.

Therefore, through Eq. (9) that relating $\mathrm{cl}$ and $\sigma$, one of the unknown roughness parameters can be reduced. Once the ACF was predefined, by combined using only one further equation (Eq. 11) as described in Section 3.1, it is possible to completely characterize the three roughness parameters and subsequently use them in the AIEM to inverse soil moisture.

During the second step, soil dielectric constant is estimated using an iterative least squares minimization algorithm, which minimize the difference between observed and AIEM computed backscattering coefficients. Dobson model (Dobson et al., 1985) was used to convert soil dielectric constant into soil moisture values. The cost function is defined as

$J=\left[\sigma_{\mathrm{obs}}^{0}-\sigma_{\mathrm{est}}^{0}(m v)\right]^{2}$

where $\sigma_{\text {obs }}^{0}$ is the radar observation, $\sigma_{\text {est }}^{0}(m v)$ represents the estimation obtained from the AIEM simulations and $m v$ is the soil moisture that needs to be determined.

\subsection{Study area}

The study was carried out at one of the WATER foci experimental areas (FEAs). WATER is a simultaneous airborne, satellite-borne, and ground-based remote-sensing experiment taking place in the Heihe River Basin, the second largest inland river basin in an arid region of northwestern China ( $\mathrm{Li}$ et al., 2009). One of the most important components of the WATER is the arid region hydrology experiment (ARHE).

Linze grassland $\left(\mathrm{LZG} ; 100^{\circ} 04^{\prime} \mathrm{E}, 39^{\circ} 15^{\prime} \mathrm{N}\right)$, which covers an area of $2 \times 2 \mathrm{~km}^{2}$, locates in Linze county, Zhangye city in the middle stream of the Heihe River Basin (Fig. 1). It was selected as one of the foci experimental areas in ARHE and is the study area in this investigation. Land cover types are diverse in this region, with wetland, grassland, and farmland distributed in the vicinity. During the field campaigns conducted in the intensive observation period (IOP) from
Table 1. Ground truth measurements of soil moisture and surface roughness.

\begin{tabular}{|c|c|c|c|c|c|c|}
\hline \multicolumn{7}{|c|}{ In situ measurement } \\
\hline \multirow{2}{*}{ site } & \multicolumn{3}{|c|}{$\begin{array}{c}m v\left(\mathrm{~cm}^{3} \mathrm{~cm}^{-3}\right) \\
(27 \text { June 2008) }\end{array}$} & \multicolumn{3}{|c|}{$\sigma(\mathrm{cm})$} \\
\hline & range & mean & $\begin{array}{c}\text { standard } \\
\text { deviation }\end{array}$ & range & mean & $\begin{array}{l}\text { standard } \\
\text { deviation }\end{array}$ \\
\hline A & $0.23 \sim 0.54$ & 0.39 & 0.08 & $1.11 \sim 2.09$ & 1.51 & 0.31 \\
\hline B & $0.13 \sim 0.42$ & 0.28 & 0.05 & $0.68 \sim 4.08$ & 1.40 & 0.53 \\
\hline $\mathrm{C}$ & & N/A & & $0.58 \sim 4.46$ & 1.28 & 0.66 \\
\hline $\mathrm{D}$ & $0.02 \sim 0.20$ & 0.09 & 0.05 & & N/A & \\
\hline $\mathrm{E}$ & $0.08 \sim 0.34$ & 0.25 & 0.05 & & N/A & \\
\hline
\end{tabular}

May to August 2008, five experimental sites (ESs), each $360 \times 360 \mathrm{~m}^{2}$ in size, were established (Fig. 2). Most of the grassland areas (including ESs A, B, and C) were severely encrusted with salt and alkali materials. Alfalfa and barley were planted at sites $\mathrm{D}$ and $\mathrm{E}$, both of them are irrigated farmland.

\subsection{Ground truth measurements}

Ground truths, including soil moisture, land surface temperature $(T)$, and bulk density, were collected at all five ESs concurrently with radar acquisitions. A three-level stratified sampling strategy, illustrated in Fig. 2, was designed to collect ground truths. The elementary sampling plots (ESP), which is embedded within each ES, covering an area of approximately $120 \times 120 \mathrm{~m}^{2}$ in a grid pattern at $20 \mathrm{~m}$ spacing, is assumed to be representative of entire ES in which 49 soil samples were collected.

Concurrently with radar overpasses on 27 June 2008, ground measurements were carried out from 10:00 a.m. to 01:00 p.m. (Beijing Time) (within $\pm 2 \mathrm{~h}$ of the satellite overpass) at every ESP. The moisture contents of sites D and $\mathrm{E}$ were measured by time domain reflectometry (TDR). Gravimetric sampling method was used at sites A and B due to strong salinization effect. At site $\mathrm{C}$, soil moisture measurement was not carried out. Soil moisture was sampled for the topsoil layer $(5 \mathrm{~cm})$, which is assumed as the maximum penetration depth by ASAR, at a frequency of $5.3 \mathrm{GHz}$. Soil bulk density was measured in order to transform gravimetric content into volumetric soil moisture content. Soil texture was analyzed in the laboratory. No rainfall and tillage practice were recorded in the time windows of satellite acquisitions, thus, surface roughness is assumed to be invariant during these dates. Surface roughness measurements were conducted at non-vegetated sites A, B, and C to deduce the $\mathrm{ACF}$ as a prior roughness information. Detailed sampling of soil moisture and roughness is summarized in Table 1 and other soil properties are summarized in Table 2. 


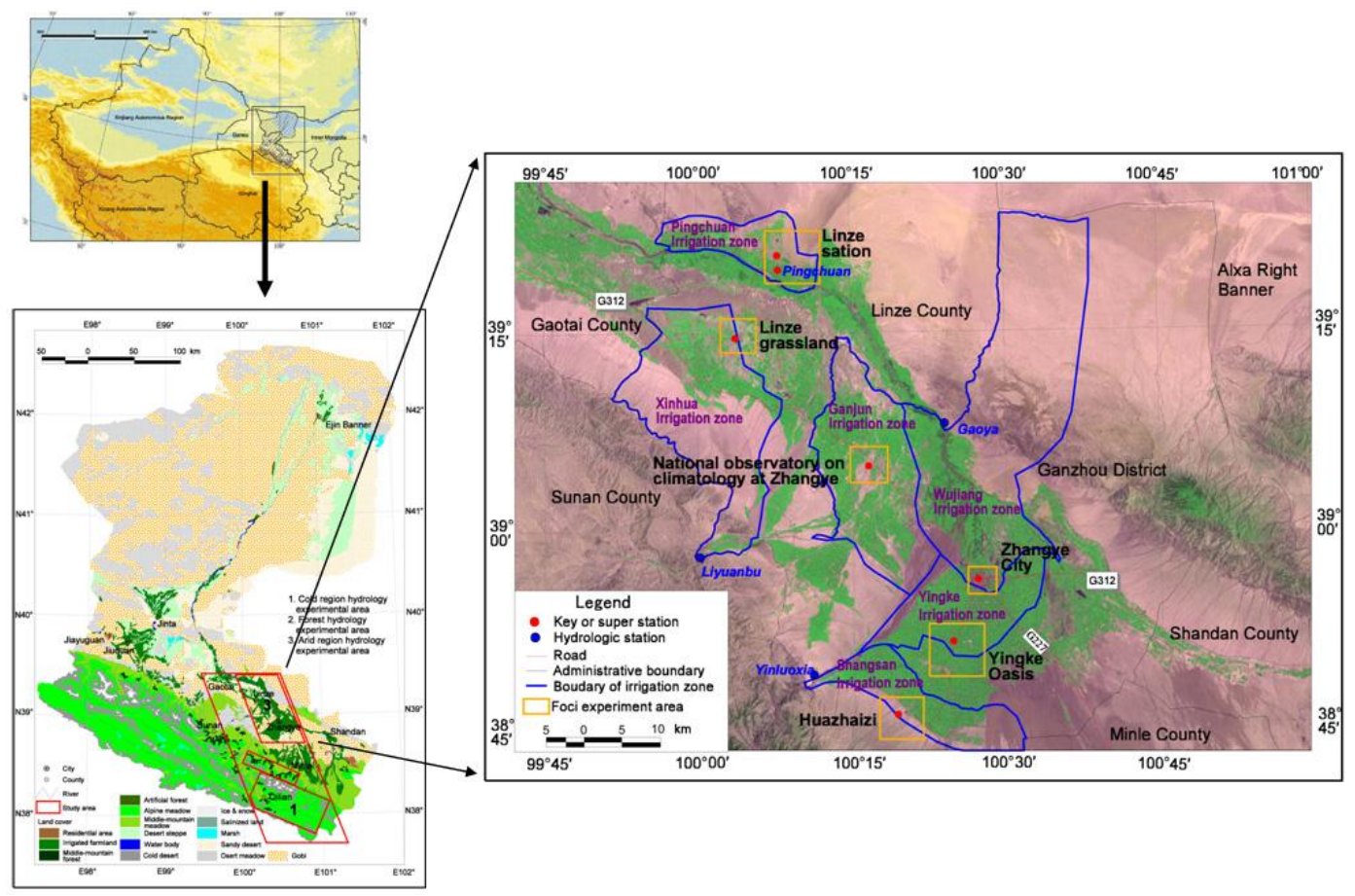

Fig. 1. Locations of the Linze grassland in the arid region hydrology experiment area (right) in the Heihe River Basin (bottom left).

Table 2. Summary of the parameter values used in the Dobson dielectric mixing model and the AIEM.

\begin{tabular}{|c|c|c|c|}
\hline Parameters & \multicolumn{3}{|c|}{ Value } \\
\hline$f(\mathrm{GHz})$ & \multicolumn{3}{|c|}{5.3} \\
\hline$\theta\left({ }^{\circ}\right)$ & \multicolumn{3}{|c|}{$18.4,28.5,43.9$} \\
\hline Initial value of $m v\left(\mathrm{~cm}^{3} \mathrm{~cm}^{-3}\right)$ & \multicolumn{3}{|c|}{0.2} \\
\hline Land surface temperature $T\left(^{\circ}\right)$ & \multicolumn{3}{|c|}{27} \\
\hline $\begin{array}{l}\text { Soil density } \\
\left(\mathrm{g} \mathrm{cm}^{-3}\right)\end{array}$ & $\begin{array}{l}\text { specific density } \\
2.70\end{array}$ & & $\begin{array}{l}\text { bulk density } \\
1.31\end{array}$ \\
\hline Soil porosity & \multicolumn{3}{|c|}{0.51} \\
\hline Soil texture $(\%)$ & $\begin{array}{l}\text { sand } \\
20.5\end{array}$ & & $\begin{array}{l}\text { clay } \\
8.5\end{array}$ \\
\hline$\sigma(\mathrm{cm})$ & $\begin{array}{l}\min \\
0.3\end{array}$ & $\begin{array}{l}\max \\
3.0\end{array}$ & $\begin{array}{l}\text { increment } \\
0.1\end{array}$ \\
\hline $\mathrm{cl}(\mathrm{cm})$ & $\begin{array}{l}\min \\
3\end{array}$ & $\begin{array}{l}\max \\
35\end{array}$ & $\begin{array}{l}\text { increment } \\
2\end{array}$ \\
\hline
\end{tabular}

As for the parameters used in the water cloud model, vegetation water content was measured only at site $E$ on 18 June 2008. Due to limited resources, sufficient canopy properties measurements were not obtained. Therefore, vwc at site D was inferred on the basis of local growing status and constants $A$ and $b$ used in the water cloud model were
Table 3. Vegetation parameters used in the water cloud model.

\begin{tabular}{lclll}
\hline site & $A$ & $b$ & vwc $\left(\mathrm{kg} \mathrm{m}^{-2}\right)$ & land cover \\
\hline D & 0.01 & 0.084 & 0.3 & alfalfa after harvest \\
E & 0.05 & 0.3 & 1.46 & barley in mature stage \\
\hline
\end{tabular}

not able to be calibrated based on the ground truth measurements. Thus, their estimates were referenced from Bindlish and Barros (2001). Parameters used for vegetation effects correction are shown in Table 3.

\subsection{Radar imagery}

ASAR operates at C-band $(5.3 \mathrm{GHz})$ and was launched onboard ENVISAT in 2002. ASAR features enhanced capability in terms of coverage, with selectable incidence angles, polarizations, and operational mode configurations. In this investigation, three contiguous ASAR images in alternating polarization precision (APP) modes with different incidence angles ranging from IS $1\left(18.4^{\circ}\right)$ to IS7 $\left(43.9^{\circ}\right)$ were acquired. The orbital information of the images is presented in Table 4.

Absolute calibration of the ASAR images was performed to transform the radar signals (DN values) into backscattering coefficients $\left(\sigma^{0}\right)$. After radiometric calibration, the speckle noise in the images was filtered by a $5 \times 5$ enhanced Lee filter. Changes in the local incidence angle were not 


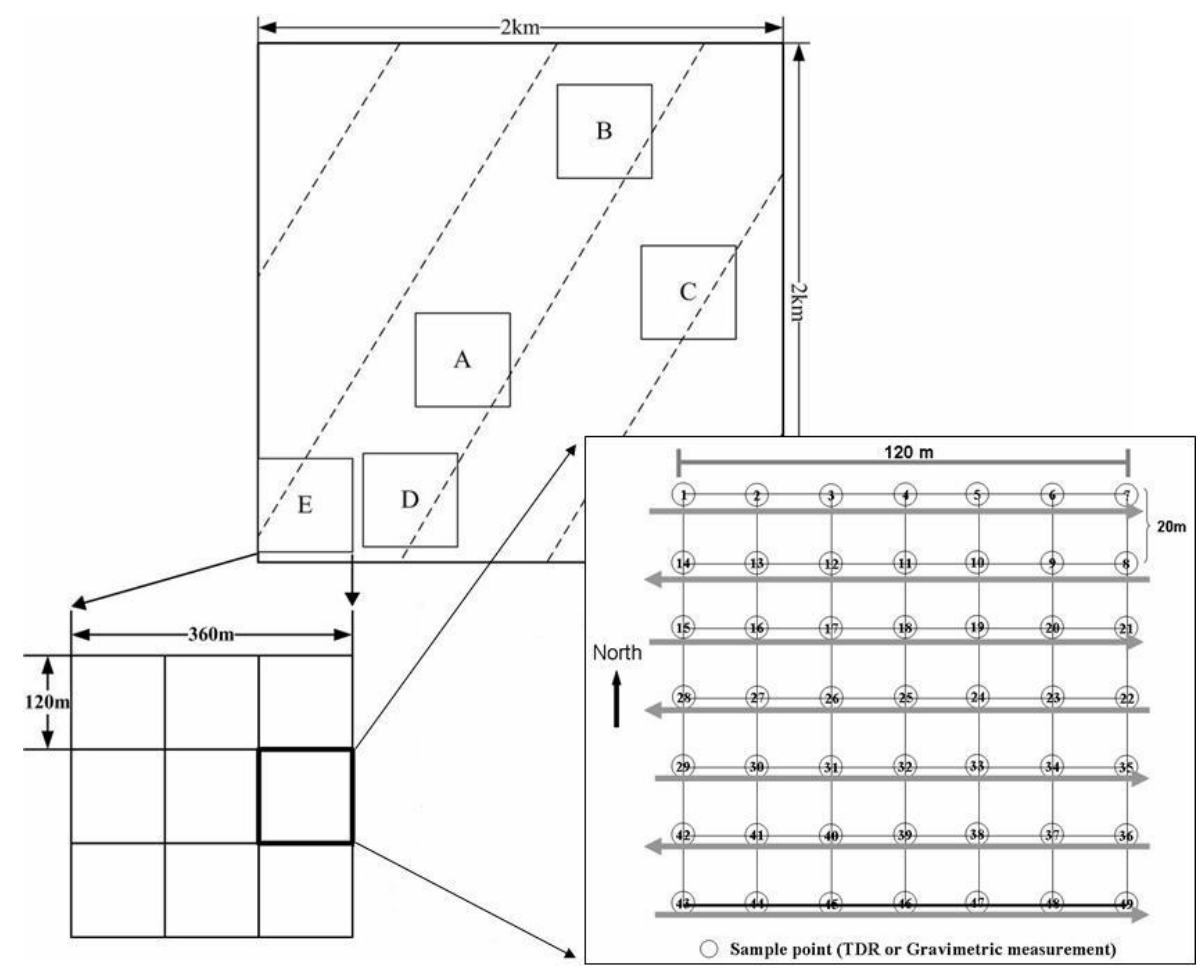

Fig. 2. The three-level soil moisture field sampling strategy.

considered because the topography is flat in the study area. Geolocation was performed according to the UTM projection system using a Landsat ETM+ image as a reference. The registration error was within one pixel. After image processes, the resolution of the imagery used for the estimation of roughness and soil moisture is $30 \mathrm{~m}$. Figure 3 illustrates the subsets of the processed images of the study area.

\section{Results and discussion}

\subsection{Mapping surface roughness and soil moisture}

As has been mentioned in Sect. 2.2, the specific function of Eq. (8) needs to be obtained through statistical analysis. In the current study, all of the three scenes of ASAR images with $\mathrm{HH}$ polarization were involved in the pairwise calculation. A forward simulation was carried out based on the AIEM, with $\sigma$ ranging from 0.3 to $3.0 \mathrm{~cm}$ and $\mathrm{cl}$ from 3 to $35 \mathrm{~cm}$, and soil moisture was set as $0.2 \mathrm{~cm}^{3} \mathrm{~cm}^{-3}$. From the analysis of in situ roughness measurements, the correlation function type is found to be fit for the exponential one.

Through statistical analysis, it was found the best regressed relationship was generated from the pair of IS1 and IS7 swaths. The simulated data were fitted by a cubic polynomial function, which is expressed as
Table 4. List of ASAR images used in this study.

\begin{tabular}{lccc}
\hline \multicolumn{3}{c}{ ASAR images } \\
\hline Date & Polarization & Swath & Central lat/long (degree) \\
\hline 25 June 2008 & HH/HV & IS3, 28.5 & $38.97 / 100.23$ \\
27 June 2008 & HH/HV & IS7, 43.9 & $38.97 / 100.08$ \\
28 June 2008 & HH/HV & IS1, 18.4 & $38.89 / 100.48$ \\
\hline
\end{tabular}

$$
\begin{aligned}
Z s= & -0.0009\left(\Delta \sigma_{\mathrm{IS} 1-\mathrm{IS} 7}\right)^{3}+0.0142\left(\Delta \sigma_{\mathrm{IS} 1-\mathrm{IS} 7}\right)^{2} \\
& -0.0813\left(\Delta \sigma_{\mathrm{IS} 1-\mathrm{IS} 7}\right)+0.3545
\end{aligned}
$$

where, $\Delta \sigma_{\text {IS1-IS7 }}$ denotes the difference in backscattering coefficient between two incidence angles (i.e., IS1 and IS7 swaths) at $\mathrm{HH}$ polarization. As shown in Fig. 4, this function fits the simulation data fairly good with a coefficient of determination $\left(R^{2}\right)$ equal to 0.94 . For the other two pairs, $\Delta \sigma_{\text {IS1-IS3 }}$ and $\Delta \sigma_{\text {IS3-IS7 }}$, the $R^{2}$ values are equal to 0.85 and 0.89 respectively. From a temporal viewpoint, using IS1-IS7 pair is also the optimal choice since the two scenes were acquired on successive dates (Table 4). Accordingly, distributed $Z s$ information can be obtained based on these two images. Small values of $Z s$ correspond to smooth conditions, due to small values of $\sigma$ and/or large values of cl. In contrast, large values of $Z s$ represent rough surfaces. 


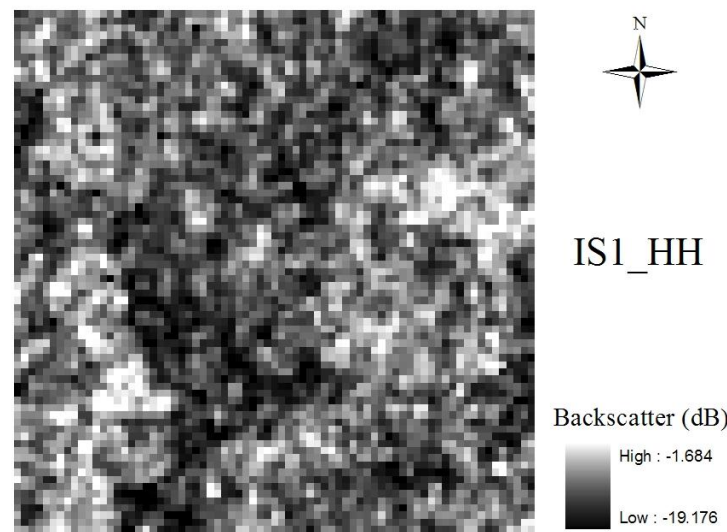

(a)
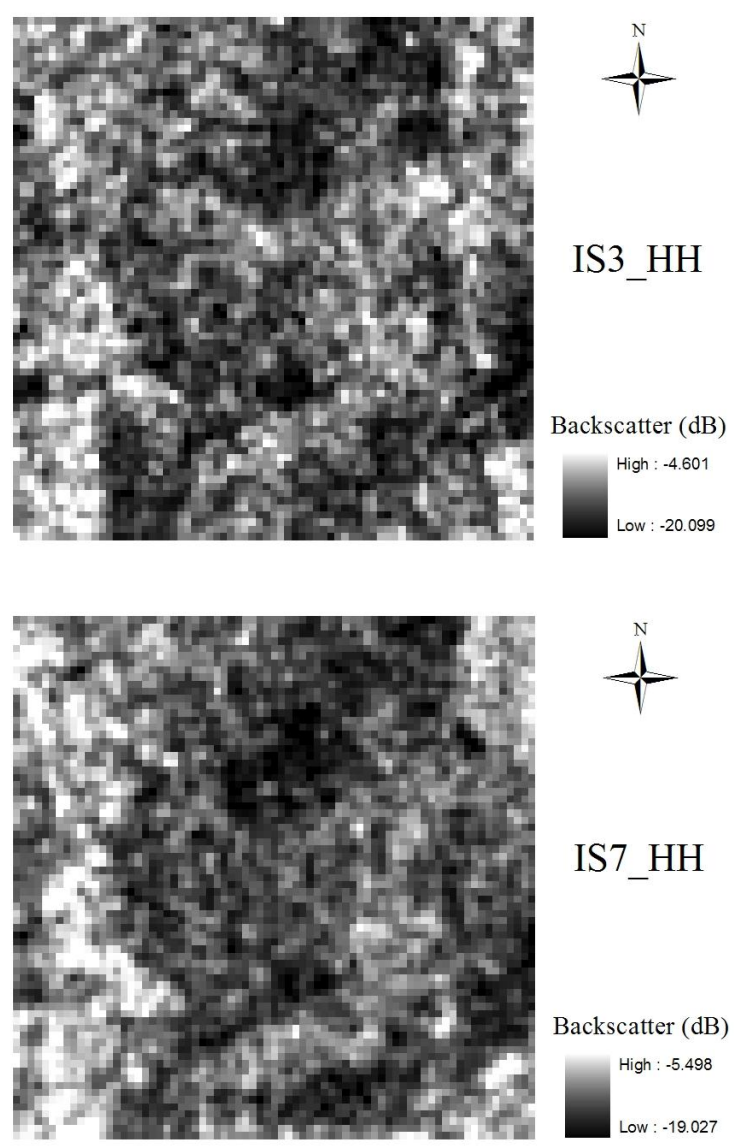

Fig. 3. Segment scenes of the processed images in the regions of the study area, (a), (b), and (c) corresponding to the IS1, IS3, and IS7 swaths, respectively.

By specifying an incidence angle of $43.9^{\circ}$ at $\mathrm{HH}$ polarization, the values of those coefficients (i.e., $\delta, \zeta, \mu$, and $\eta$ ) involved in Eq. (9) can be obtained based on Baghdadi et al. (2006b). The relationship between $\mathrm{cl}$ and $\sigma$ is

$\mathrm{cl}=7.62 \sigma^{1.44}$

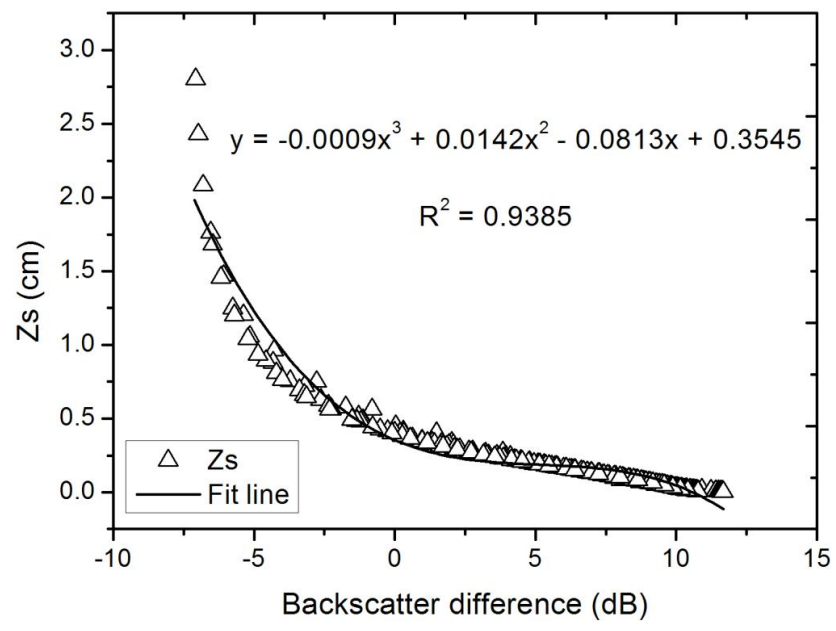

Fig. 4. Sketch map of the relationship between $Z s$ and $\Delta \sigma_{\text {IS1-IS7 }}$ (incidence angles of $18.4^{\circ}$ and $43.9^{\circ}$ ) provided by Eq. (11).

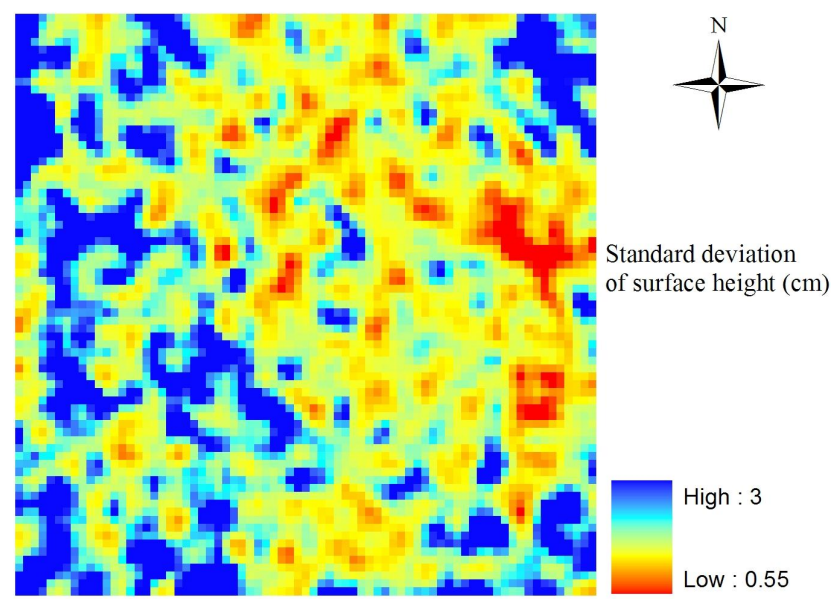

Fig. 5. Estimated results of the standard deviation of surface height from multi-angular ASAR images.

Substituting Eq. (12) into Eq. (11) with the combination of Eq. (7), $\sigma$ and $\mathrm{cl}$ can be calculated for every pixel. As an example, the distribution of the standard deviation of surface height is shown in Fig. 5. The results shown most of the experimental area is characterized by high values of $\sigma$.

After obtaining the roughness, soil moisture distribution over the study area was estimated using the inversion procedure described in Sect. 2.2. Results are illustrated in Fig. 6. The dominant yellow colors in the map represent low levels of soil moisture. In general, saline effect may lead to an underestimate of soil moisture. Therefore, the low soil moisture retrieval results distribution is coherent with salinized sparse grass covered areas. Compared to the land use map (Fig. 7), the blue colors correspond to higher soil water content which appeared mainly in farmlands (west part) and wetland (east part). Except for a small area in the lower 


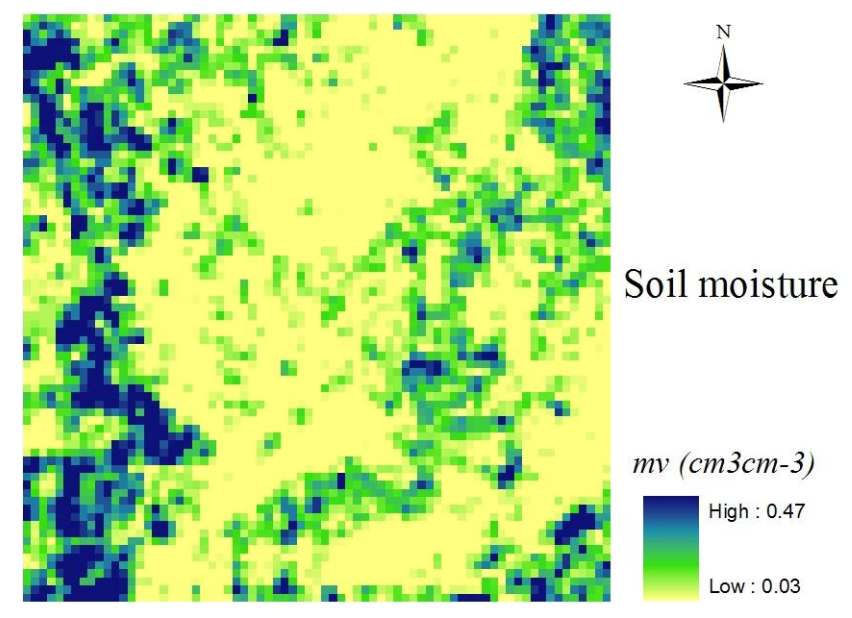

Fig. 6. Retrieved soil moisture based on the obtained surface roughness estimates.

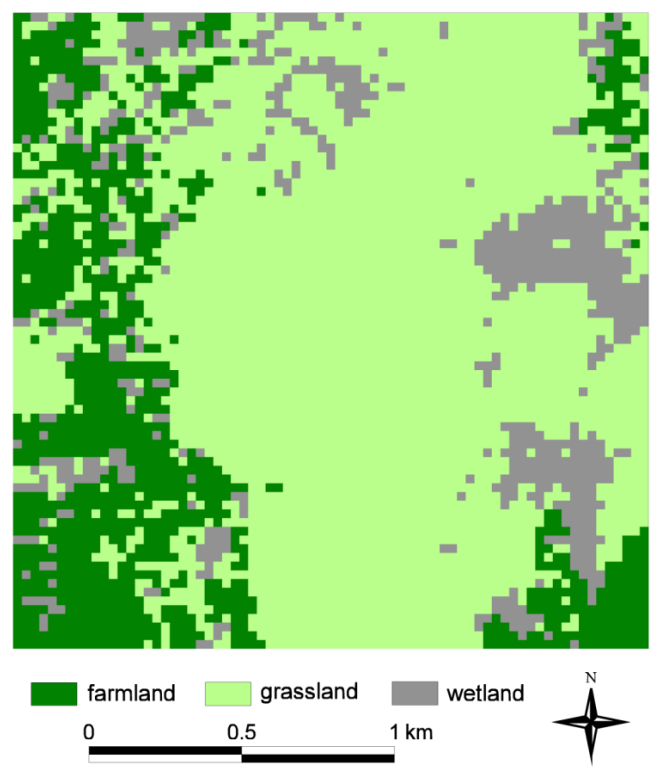

Fig. 7. Land use map of the study area.

part of the study area, the spatial pattern of $m v$ distribution is reasonable, agreeing well with the local situation since an irrigation event had taken place 5 days before, thus the vegetated areas were still wet but the sparse grass covered areas had turned into dry condition due to considerably high evaporation in this arid region.

\subsection{Validation}

Due to strong salinization in the grassland sites A, B, and C, roughness and soil moisture estimation were not performed but for sites D and E. In addition, roughness results could not be validated because in situ roughness measurements were not conducted at sites $\mathrm{D}$ and $\mathrm{E}$ due to vegetation obstacles.

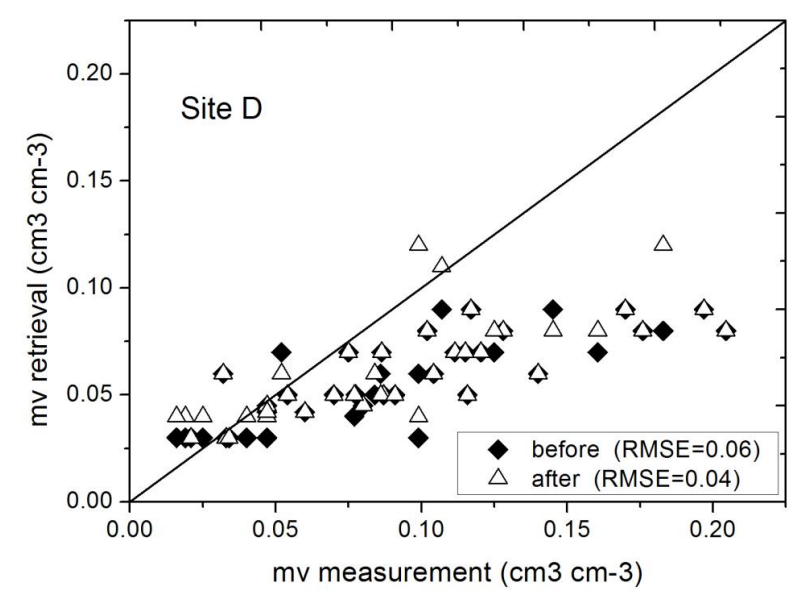

(a)

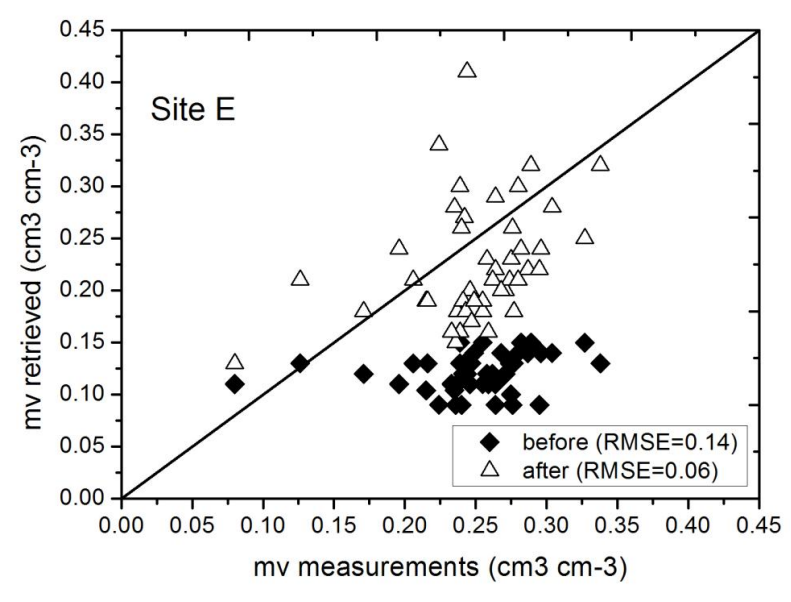

(b)

Fig. 8. Comparison between soil moisture estimated from radar imagery and in situ measurements at (a) site D and (b) site E, before $(\bullet)$ and after $(\Delta)$ the correction of vegetation effect.

As shown in Fig. 8, soil moisture estimates were compared against the in situ TDR measurements. Two groups of scatter points were plotted in each diagram, i.e., before and after the correction of canopy interference for each study site. For each ES, 45 points of in situ measurements were used to validate the estimates from SAR imagery while other 4 soil samples were discarded for their obviously irrational values. The results demonstrate that, for site $\mathrm{D}$, the root mean square error (RMSE) and the mean error (ME) of $m v$ after the correction of vegetation effect are $0.04 \mathrm{~cm}^{3} \mathrm{~cm}^{-3}$ and $-0.02 \mathrm{~cm}^{3} \mathrm{~cm}^{-3}$, respectively. For site E, the RMSE and the ME of $m v$ after the correction of vegetation effect are $0.06 \mathrm{~cm}^{3} \mathrm{~cm}^{-3}$ and $-0.03 \mathrm{~cm}^{3} \mathrm{~cm}^{-3}$, manifesting that the soil moisture is slightly underestimated in both sites. The correlation coefficient $(R)$ between observed and estimated soil moisture values at sites D and E are 0.70 and 0.35 , respectively. Compared the RMSEs and the correlation coefficients, it is shown that the results at site $\mathrm{D}$ are better than those at site E. This might due to the fact that (1) canopy in 
site $\mathrm{E}$ is much thicker than $\mathrm{D}$ and (2) site $\mathrm{D}$ is more homogeneous than site $\mathrm{E}$.

\subsection{Vegetation effect}

The results indicate that vegetation has a very significant effect on soil moisture estimation. For site D, the RMSE and the ME of $m v$ without correcting the vegetation effect are $0.06 \mathrm{~cm}^{3} \mathrm{~cm}^{-3}$ and $-0.03 \mathrm{~cm}^{3} \mathrm{~cm}^{-3}$, respectively. For site $\mathrm{E}$, the two values are $0.14 \mathrm{~cm}^{3} \mathrm{~cm}^{-3}$ and $-0.12 \mathrm{~cm}^{3} \mathrm{~cm}^{-3}$. It is evident that thin canopy (alfalfa stubble) at site D slightly impact $m v$ estimations while the thicker canopy presented at site E could yield more extinction and result in a significant underestimation of $m v$.

Undoubtedly, canopy effect should be minimized in order to guarantee the applicability of the AIEM. The parameter values of $A, b$, and vwc, are all important for using the water cloud model to correct the vegetation effect. Usually, $A$ and $b$ can be calibrated from observations but these are not available in this study. A sampling of vwc did take place at site E, but preceded the SAR data acquisition nearly 10 days. Thus, the parameters used in vegetation correction are mainly derived from literatures. It is suggested that although the $m v$ estimates were improved after using the water cloud model, more satisfied results could be expected by using some sophisticated vegetation models or adequate vegetation measurements (Joseph et al., 2010).

\subsection{Error analysis}

It can be seen in Fig. 8 that at sites D and E, the estimated values of $m v$ are lower than those measured in situ, even after the correction of vegetation effects. It is supposed that this is partially caused by the difference of sensing depth for soil media between remote sensing and in situ measurements. Radar signals in $\mathrm{C}$ band essentially perceives the dielectric properties of the superficial soil layer (usually around or less than $1 \mathrm{~cm})$. On the contrary, for TDR measurements used for the validation, the detected $m v$ is the integral value through the entire sampling depth $(\sim 5 \mathrm{~cm})$ in the measured soil volume. The uppermost soil layer is usually drier than deeper layers, especially the case in arid regions. This probably could be an explanation to the underestimation of $m v$ as reported in previous investigations (Escorihuela et al., 2010; Wagner et al., 2007).

Furthermore, we are quite aware that some biases in the results can be attributed to the method used to acquire roughness parameters. Equation (12), which is crucial to the derivation of $\sigma$ and $\mathrm{cl}$, inherently depends on the selection of data acquisitions and study sites. In spite of the fact that a large quantity of images and corresponding in situ measurements were involved in the deduction of the coefficients used in Eq. (9) presented by Baghdadi et al. (2006b), it is conceivable that this empirical relationship could contribute more or less errors when it is deployed in our study environment.
Uncertainties also arise from the definition of Eq. (11), primarily in two aspects:

- The specific form of the function is greatly impacted by the values of the input parameters used in the forward simulations. For example, the expression of the Eq. (11) evidently differs from the one proposed by Zribi and Dechambre (2002). The difference can be attributed to the dissimilar domains of the input roughness parameters values.

- One of the basic hypotheses for using multidimensionality method is the land surface properties are assumed to be unchanged over the satellite data acquisition period. Unfortunately, at present, no SAR sensors onboard satellite platforms have been able to offer multi-angular measurements simultaneously. Thus, a variant of soil moisture is expected during data acquisitions, especially when the radar scenes were collected from different dates. Accordingly, some uncertainties can be ascribed to this aspect although the temporal gap of the images used in this study is very small (1 day) to the revisit capabilities of existed space-borne SAR systems.

\subsection{Discussion}

The main purpose of this paper is to develop a method that can reduce the impact of roughness on soil moisture retrieval. In the past few years, some studies have addressed on this issue, both for active and passive microwave remote sensing. They shall be compared with the current study.

Lievens et al. (2011) proposed a statistical model to estimate roughness parameter based solely on a normalized backscatter observation, subsequently, the deduced roughness can be used in the inversion of soil moisture by the IEM. Saleh et al. (2009) reported a two-step and two-parameter inversion approach. Joseph et al. (2010) also estimated surface roughness parameters by tuning known data sets. It can be perceived that these investigations adopted similar retrieval strategies as compared to the proposed method in this study. That is, first, the roughness parameters that are needed by the radiative transfer models were calibrated or estimated. Then, soil moisture retrievals were conducted based on the obtained roughness estimates. In comparison to our case study, the main difference is existed in the roughness derivation step. The above studies used training data sets consisting of remote sensed observations and corresponding field measurements, in association with radiative transfer models (e.g., IEM). While our study applied AIEM simulations and the $\mathrm{cl}$ calibration approach proposed by Baghdadi et al. (2006b), since this calibration scheme was also developed based on abundant data sets and has been proven effective (ÁlvarezMozos et al., 2008; Baghdadi et al., 2006b).

With respect to the approaches for the correction of vegetation effects, Joseph et al. (2010) proposed a novel method 
(ratio method) and proved that it is superior to the water cloud model when vegetation scattering component is dominant. The general accuracy of the soil moisture retrievals was obtained with an RMSE level of $0.04 \mathrm{~cm}^{3} \mathrm{~cm}^{-3}$ across two frequencies observations. Good agreement was found between the inversion results and the ground-truth measurements in semi-arid regions (Zribi et al., 2011). The retrieved soil moisture mean errors were equal to $0.039 \mathrm{~cm}^{3} \mathrm{~cm}^{-3}$ for olive trees areas. The water cloud model was also used in this study, and leaf area index values were used to estimate vegetation water content, which in turn results in accurate soil moisture estimates in wheatland, with a mean RMSE of $0.058 \mathrm{~cm}^{3} \mathrm{~cm}^{-3}$. To use these methods depends on the availability of reliable vegetation water content data. Unfortunately, the resources in the current study are not able to provide appropriate data sets to perform the specific parameterization scheme to derive or calibrate the vegetation water content.

Both Pathe et al. (2009) and Mladenova et al. (2010) applied the change detection method by using ASAR global monitoring data to derive or validate soil moisture in different test sites. The RMSEs of these reported soil moisture estimations were generally on the orders of $0.04 \mathrm{~cm}^{3} \mathrm{~cm}^{-3}$ to $0.14 \mathrm{~cm}^{3} \mathrm{~cm}^{-3}$ over different land covers and scales. Wagner et al. (2007) compared four kinds of published global soil moisture products between each individual data set in the Duero basin in Spain. In total, the RMSE is around $0.06 \mathrm{~cm}^{3} \mathrm{~cm}^{-3}$ across different satellite estimates. Therefore, the RMSE of $0.06 \mathrm{~cm}^{3} \mathrm{~cm}^{-3}$ for soil moisture estimates after vegetation effect correction in the current study is comparable to the results referred above. It is probably an acceptable magnitude to be of use for various applications (Wagner et al., 2007), although the value is higher than the targeted error of $0.04 \mathrm{~cm}^{3} \mathrm{~cm}^{-3}$ for AMSR-E (Njoku et al., 2003) and SMOS products (Kerr et al., 2001). It can be concluded that both sensors and retrieval methods must be carefully chosen in order to achieve more accurate soil moisture retrievals depending on the characteristics of the study area and available data sets, particularly if the operational retrieval application is envisaged (Pathe et al., 2009).

\section{Conclusions}

Previous studies have demonstrated that it is still problematic to accurately assess soil moisture using theorized models, e.g., IEM or AIEM, if the surface roughness is not appropriately quantified. Conventionally, areal roughness can be obtained from parameterization, ancillary datasets, or by upscaling point measurements. Although these methods are practicable in some way, it is still worth seeking a direct way of quantifying the spatial distribution of roughness at the pixel scale.

The investigation presented in this paper proposes a promising two-step retrieval strategy to estimate surface roughness and soil moisture without auxiliary information. Both standard deviation of surface height and correlation length can be estimated from multi-angular SAR observations. Then, the derived roughness parameters were used in the inversion of soil moisture based on the AIEM. An evaluation was carried out in the middle reaches of the Heihe River Basin and the results show that this method is reliable. After a correction of vegetation effect by using the water cloud model, the resulting RMSE of soil moisture range between $0.04 \mathrm{~cm}^{3} \mathrm{~cm}^{-3}$ to $0.06 \mathrm{~cm}^{3} \mathrm{~cm}^{-3}$. It is suggested that the errors of the estimation can be attributed to the presence of remaining vegetation effects, the semi-empirical deduction of surface roughness, and the difference in sensing depths between SAR and TDR probe measurements. In summary, the proposed method is shown to be an effective method for surface roughness characterization and soil moisture mapping at regional scale, based solely on satellite data instead of using ancillary information, such as point measurements by pinprofilometer. Therefore, not only time and resources can be saved, the uncertainties in association with the upscaling of point roughness measurement can be avoided as well.

Potential future works in this area should extend the application of the proposed method over other study regions. Besides, with more and more satellites carrying payloads of polarimetric SAR, such as ALOS-PALSAR, Radarsat-2, and TerraSAR constellation, the usage of the polarimetricdecomposition technique for soil moisture derivation can be anticipated. This technique facilitates the separation of the scattering signature into different parts attributed to different objective properties in order to obtain the exclusive contribution of soils underlying canopy layer (Hajnsek et al., 2009). Furthermore, airborne 3-D light detection and ranging (LIDAR) systems may make it possible to effectively collect surface roughness information over large areas, thereby solving the problem of acquiring statistically representative surface roughness measurements. Such a development would dramatically conduce to the inversion of soil moisture (Wagner and Pathe, 2004).

Acknowledgements. This work is supported by the Chinese Academy of Sciences Action Plan for West Development Project "Watershed Allied Telemetry Experimental Research (WATER)" (grant number KZCX2-XB2-09), the NSFC (National Science Foundation of China) projects (grant numbers: 40925004 and 40771036), and the national high-tech program (863) project "A Common Software for Multi-Source Remote Sensing Data Assimilation" (grant number 2009AA12Z130) and project 2009AA12Z1463. The authors would also like to thank ESA for the provision of ASAR data in the framework of the Dragon 2 program (Project ID 5322). Special thanks are extended to all crew members at the field campaigns. We would also like to thank the anonymous reviewers for their constructive suggestions and comments.

Edited by: L. Pfister 


\section{References}

Álvarez-Mozos, J., González-Audícana, M., Casali, J., and Larrañaga, A.: Effective versus measured correlation length for radar-based surface soil moisture retrieval, Int. J. Remote Sens., 29, 5397-5408, doi:10.1080/01431160802036367, 2008.

Attema, E. P. and Ulaby, F. T.: Vegetation modeled as a water cloud, Radio Sci., 13, 357-364, 1978.

Baghdadi, N. and Zribi, M.: Evaluation of radar backscatter models IEM, $\mathrm{OH}$ and Dubois using experimental observations, Int. J. Remote Sens., 27, 3831-3852, doi:10.1080/01431160600658123, 2006.

Baghdadi, N., King, C., Chanzy, A., and Wigneron, J. P.: An empirical calibration of the integral equation model based on SAR data, soil moisture and surface roughness measurement over bare soils, Int. J. Remote Sens., 23, 4325-4340, doi:10.1080/01431160110107671, 2002.

Baghdadi, N., Gherboudj, I., Zribi, M., Sahebi, M., King, C., and Bonn, F.: Semi-empirical calibration of the IEM backscattering model using radar images and moisture and roughness field measurements, Int. J. Remote Sens., 25, 3593-3623, doi:10.1080/01431160310001654392, 2004.

Baghdadi, N., Holah, N., and Zribi, M.: Soil moisture estimation using multi-incidence and multi-polarization ASAR data, Int. J. Remote Sens., 27, 1907-1920, doi:10.1080/01431160500239032, 2006a.

Baghdadi, N., Holah, N., and Zribi, M.: Calibration of the integral equation model for SAR data in C-band and $\mathrm{HH}$ and VV polarizations, Int. J. Remote Sens., 27, 805-816, doi:10.1080/01431160500212278, 2006b.

Baghdadi, N., Cerdan, O., Zribi, M., Auzet, V., Darboux, F., ElHajj, M., and Boukheir, R.: Operational performance of current synthetic aperture radar sensors in mapping soil surface characteristics: application to hydrological and erosion modelling, Hydrol. Process., 22, 9-20, doi:10.1002/hyp.6609, 2008.

Bindlish, R. and Barros, A. P.: Multifrequency soil moisture inversion from SAR measurements with the use of IEM, Remote Sens. Environ., 71, 67-88, 2000.

Bindlish, R. and Barros, A. P.: Parameterization of vegetation backscatter in radar-based, soil moisture estimation, Remote Sens. Environ., 76, 130-137, 2001.

Brocca, L., Melone, F., Moramarco, T., Wagner, W., Naeimi, V., Bartalis, Z., and Hasenauer, S.: Improving runoff prediction through the assimilation of the ASCAT soil moisture product, Hydrol. Earth Syst. Sci., 14, 1881-1893, doi:10.5194/hess-141881-2010, 2010.

Bryant, R., Moran, M. S., Thoma, D. P., Holifield Collins, C. D., Skirvin, S., Rahman, M. M., Slocum, K., Starks, P., Bosch, D., and Gonzalez Dugo, M. P.: Measuring surface roughness height to parameterize Radar backscatter models for retrieval of surface soil moisture, IEEE T. Geosci. Remote Sens. Lett., 4, 137-141, doi:10.1109/LGRS.2006.887146, 2007.

Chen, K. S., Wu, T. D., Tsang, L., Li, Q., Shi, J., and Fung, A. K.: Emission of rough surfaces calculated by the integral equation method with comparison to three-dimensional moment method simulations, IEEE T. Geosci. Remote, 41, 90-101, 2003.

Davidson, M. W., Le Toan, T., Mattia, F., Satalino, G., Manninen, T., and Borgeaud, M.: On the characterization of agricultural soil roughness for radar remote sensing studies, IEEE T. Geosci. Remote, 38, 630-640, 2000.
Dobson, M. C., Ulaby, F. T., Hallikainen, M. T., and El-rayes, M. A.: Microwave dielectric behavior of wet soil - part II: dielectric mixing models, IEEE T. Geosci. Remote, GE-23, 35-46, 1985.

Dubois, P. C., van Zyl, J., and Engman, T.: Measuring soil moisture with imaging radars, IEEE T. Geosci. Remote, 33, 915-926, 1995.

D’Urso, G. and Minacapilli, M.: A semi-empirical approach for surface soil water content estimation from radar data without apriori information on surface roughness, J. Hydrol., 321, 297310, doi:10.1016/j.jhydrol.2005.08.013, 2006.

Escorihuela, M. J., Chanzy, A., Wigneron, J. P., and Kerr, Y. H.: Effective soil moisture sampling depth of L-band radiometry: a case study, Remote Sens. Environ., 114, 995-1001, doi:10.1016/j.rse.2009.12.011, 2010.

Fung, A. K.: Microwave scattering and emission models and their applications, Artech House Inc., Norwood, MA, 1994.

Fung, A. K., Li, Z., and Chen, K. S.: Backscattering from a randomly rough dielectric surface, IEEE T. Geosci. Remote, 30, 356-369, 1992.

Hajnsek, I., Jagdhuber, T., Schon, H., and Papathanassiou, K. P.: Potential of estimating soil moisture under vegetation cover by means of PolSAR, IEEE T. Geosci. Remote, 47, 442-454, doi:10.1109/TGRS.2008.2009642, 2009.

Holah, N., Baghdadi, N., Zribi, M., Bruand, A., and King, C.: Potential of ASAR/ENVISAT for the characterization of soil surface parameters over bare agricultural fields, Remote Sens. Environ., 96, 78-86, doi:10.1016/j.rse.2005.01.008, 2005.

Jackson, T. J., Le Vine, D. M., Swift, C. T., Schmugge, T. J., and Schiebe, F. R.: Large area mapping of soil moisture using the ESTAR passive microwave radiometer in Washita'92, Remote Sens. Environ., 54, 27-37, 1995.

Jackson, T. J., Gasiewski, A. J., Oldak, A., Klein, M., Njoku, E. G., Yevgrafov, A., Christiani, S., and Bindlish, R.: Soil moisture retrieval using the $\mathrm{C}$-band polarimetric scanning radiometer during the southern great plains 1999 experiment, IEEE T. Geosci. Remote, 40, 2151-2161, 2002.

Joseph, A. T., van der Velde, R., O’Neill, P. E., Lang, R., and Gish, T.: Effects of corn on C- and L-band radar backscatter: A correction method for soil moisture retrieval, Remote Sens. Environ., 114, 2417-2430, doi:10.1016/j.rse.2010.05.017, 2010.

Kerr, Y. H., Waldteufel, P., Wigneron, J. P., Martinuzzi, J. M., Font, J., and Berger, M.: Soil moisture retrieval from space: the soil moisture and ocean salinity (SMOS) mission, IEEE T. Geosci. Remote, 39, 1729-1735, 2001.

Li, X., Li, X., Li, Z., Ma, M., Wang, J., Xiao, Q., Liu, Q., Che, T., Chen, E., Yan, G., Hu, Z., Zhang, L., Chu, R., Su, P., Liu, Q., Liu, S., Wang, J., Niu, Z., Chen, Y., Jin, R., Wang, W., Ran, Y., Xin, X., and Ren, H.: Watershed Allied Telemetry Experimental Research, J. Geophys. Res., 114, D22103, doi:10.1029/2008JD011590, 2009.

Lievens, H., Vernieuwe, H., Álvarez-Mozos, J., De Baets, B., and Verhoest, N. E. C.: Error in radar-derived soil moisture due to roughness parameterization: an analysis based on synthetical surface profiles, Sensors, 9, 1067-1093, doi:10.3390/s90201067, 2009.

Lievens, H., Verhoest, N. E. C., De Keyser, E., Vernieuwe, H., Matgen, P., Álvarez-Mozos, J., and De Baets, B.: Effective roughness modelling as a tool for soil moisture retrieval from C- and L-band SAR, Hydrol. Earth Syst. Sci., 15, 151-162, 
doi:10.5194/hess-15-151-2011, 2011.

Loew, A., Ludwig, R., and Mauser, W.: Derivation of surface soil moisture from ENVISAT ASAR wide swath and image mode data in agricultural areas, IEEE T. Geosci. Remote, 44, 889-899, doi:10.1109/TGRS.2005.863858, 2006.

Mladenova, I., Lakshmi, V., Walker, J. P., Panciera, R., Wagner, W., and Doubkova, M.: Validation of the ASAR global monitoring mode soil moisture product using the NAFE'05 data set, IEEE T. Geosci. Remote, 48, 2498-2508, doi:10.1109/TGRS.2010.2040746, 2010.

Moran, M. S., Peters-Lidard, C. D., Watts, J. M., and McElroy, S.: Estimating soil moisture at the watershed scale with satellitebased radar and land surface models, Can. J. Remote Sens., 30, $1-22,2004$.

Njoku, E. G. and Entekhabi, D.: Passive microwave remote sensing of soil moisture, J. Hydrol., 184, 101-129, 1996.

Njoku, E. G., Jackson, T. J., Lakshmi, V., Chan, T. K., and Nghiem, S. V.: Soil moisture retrieval from AMSR-E, IEEE T. Geosci. Remote, 41, 215-229, 2003.

Oh, Y., Sarabandi, K., and Ulaby, F. T.: An empirical model and an inversion technique for radar scattering from bare soil surfaces, IEEE T. Geosci. Remote, 30, 370-381, 1992.

Oh, Y., Sarabandi, K., and Ulaby, F. T.: Semi-empirical model of the ensemble-averaged differential Meuller matrix for microwave backscattering from bare soil surfaces, IEEE T. Geosci. Remote, 40, 1348-1355, 2002.

Parajka, J., Naeimi, V., Blöschl, G., and Komma, J.: Matching ERS scatterometer based soil moisture patterns with simulations of a conceptual dual layer hydrologic model over Austria, Hydrol. Earth Syst. Sci., 13, 259-271, doi:10.5194/hess-13-259-2009, 2009.

Pathe, C., Wagner, W., Sabel, D., Doubkova, M., and Basara, J. B.: Using ENVISAT ASAR global mode data for surface soil moisture retrieval over Oklahoma, USA, IEEE T. Geosci. Remote, 47, 468-480, doi:10.1109/TGRS.2008.2004711, 2009.

Rahman, M. M., Moran, M. S., Thoma, D. P., Bryant, R., Sano, E. E., Holifield Collins, C. D., Skirvin, S., Kershner, C., and Orr, B. J.: A derivation of roughness correlation length for parameterizing radar backscatter models, Int. J. Remote Sens., 28, 3995-4012, doi:10.1080/01431160601075533, 2007.

Rahman, M. M., Moran, M. S., Thoma, D. P., Bryant, R., Holifield Collins, C. D., Jackson, T. J., Orr, B. J., and Tischler, M.: Mapping surface roughness and soil moisture using multiangle radar imagery without ancillary data, Remote Sens. Environ., 112, 391-402, doi:10.1016/j.rse.2006.10.026, 2008.

Saleh, K., Kerr, Y. H., Richaume, P., Escorihuela, M. J., Panciera, R., Delwart, S., Boulet, G., Maisongrande, P., Walker, J. P., Wursteisen, P., and Wigneron, J. P.: Soil moisture retrievals at L-band using a two-step inversion approach, Remote Sens. Environ., 113, 1304-1312, doi:10.1016/j.rse.2009.02.013, 2009.

Shi, J., Wang, J., Hsu, A. Y., O'Neill, P. E., and Engman, E. T.: Estimation of bare surface soil moisture and surface roughness parameter using L-band SAR image data, IEEE T. Geosci. Remote, 35, 1254-1266, 1997.

Sinclair, S. and Pegram, G. G. S.: A comparison of ASCAT and modelled soil moisture over South Africa, using TOPKAPI in land surface mode, Hydrol. Earth Syst. Sci., 14, 613-626, doi:10.5194/hess-14-613-2010, 2010.
Su, Z., Troch, P. A., and De Troch, F. P.: Remote sensing of bare surface soil moisture using EMAC/ESAR data, Int. J. Remote Sens., 18, 2105-2124, 1997.

Ulaby, F. T., Moore, R. K., and Fung, A. K.: Microwave remote sensing: active and passive, Vol. II - radar remote sensing and surface scattering and rmission theory, Addison-Wesley, Advanced Book Program, Reading, Massachusetts, 609 pp., 1982.

Ulaby, F. T., Moore, R. K., and Fung, A. K.: Microwave remote sensing: active and passive, Vol. III - volume scattering and emission theory, advanced systems and applications, Artech House, Inc., Dedham, Massachusetts, 1100 pp., 1986.

Verhoest, N. E. C., Lievens, H., Wagner, W., Álvarez-Mozos, J., Moran, M. S., and Mattia, F.: On the soil roughness parameterization problem in soil moisture retrieval of bare surfaces from synthetic aperture radar, Sensors, 8, 4213-4248, doi:10.3390/s8074213, 2008.

Wagner, W., Lemoine, G., and Rott, H.: A method for estimating soil moisture from ERS scatterometer and soil data, Remote Sens. Environ., 70, 191-207, 1999.

Wagner, W., Naeimi, V., Scipal, K., de Jeu, R., and MartinezFernandez, J.: Soil moisture from operational meteorological satellites, Hydrogeol. J., 15, 121-131, doi:10.1007/s10040-0060104-6, 2007.

Wagner, W. and Pathe, C.: Has SAR failed in soil moisture retrieval?, ENVISAT \& ERS Symposium, Salzburg, Austria, 610 September 2004, ESA SP-572, 1745-1751, 2004.

Wigneron, J. P., Calvet, J. C., Pellarin, T., Van de Griend, A. A., Berger, M., and Ferrazzoli, P.: Retrieving near surface soil moisture from microwave radiometric observations: Current status and future plans, Remote Sens. Environ., 85, 489-506, doi:10.1016/S0034-4257(03)00051-8, 2003.

Wigneron, J. P., Kerr, Y. H., Waldteufel, P., Saleh, K., Escorihuela, M. J., Richaume, P., Ferrazzoli, P., de Rosnay, P., Gurney, R., Calvet, J. C., Grant, J. P., Guglielmetti, M., Hornbuckle, B., Mätzler, C., Pellarin, T., and Schwank, M.: L-band microwave emission of the biosphere (L-MEB) model: description and calibration against experimental data sets over crop fields, Remote Sens. Environ., 107, 639-655, doi:10.1016/j.rse.2006.10.014, 2007.

Wu, T. D., Chen, K. S., Shi, J., and Fung, A. K.: A transition model for the reflection coefficient in surface scattering, IEEE T. Geosci. Remote, 39, 2040-2050, 2001.

Zribi, M. and Dechambre, M.: A new empirical model to retrieve soil moisture and roughness from C-band radar data, Remote Sens. Environ., 84, 42-52, 2002.

Zribi, M., Baghdadi, N., Holah, N., Fafin, O., and Guérin, C.: Evaluation of a rough soil surface description with ASARENVISAT radar data, Remote Sens. Environ., 95, 67-76, doi:10.1016/j.rse.2004.11.014, 2005.

Zribi, M., Baghdadi, N., and Guérin, C.: Analysis of surface roughness heterogeneity and scattering behavior for radar measurements, IEEE T. Geosci. Remote, 44, 2438-2444, doi:10.1109/TGRS.2006.873742, 2006.

Zribi, M., Chahbi, A., Shabou, M., Lili-Chabaane, Z., Duchemin, B., Baghdadi, N., Amri, R., and Chehbouni, A.: Soil surface moisture estimation over a semi-arid region using ENVISAT ASAR radar data for soil evaporation evaluation, Hydrol. Earth Syst. Sci., 15, 345-358, doi:10.5194/hess-15-345-2011, 2011. 